\title{
High hemoglobin is associated with increased in-hospital death in patients with chronic obstructive pulmonary disease and chronic kidney disease: a retrospective multicenter population-based study
}

Libin $\mathrm{Xu}^{1,2,3 \dagger}$, Yuanhan Chen ${ }^{2 \dagger}$, Zhen Xie ${ }^{4}$, Qiang He ${ }^{5}$, Shixin Chen ${ }^{6}$, Wenji Wang ${ }^{7}$, Guohui Liu ${ }^{8}$, Yuanjiang Liao ${ }^{9}$, Chen Lu ${ }^{10}$, Li HaO ${ }^{11}$, Jin Sun ${ }^{12}$, Wei Shi ${ }^{1,2^{*}}$, Xinling Liang ${ }^{2^{*}}$ (i) and on behalf of China collaborative study on AKI (CCS-AKI)

\begin{abstract}
Background: Chronic kidney disease (CKD) is a common comorbidity of chronic obstructive pulmonary disease (COPD). Although high hemoglobin ( $\mathrm{Hb})$ is detrimental to CKD patients, its relationship with poor outcomes in the COPD population has not been reported. This study aimed to investigate the relationship between high $\mathrm{Hb}$ and inhospital mortality and to explore reference $\mathrm{Hb}$ intervals in patients with COPD and CKD.

Methods: This retrospective study was multicenter population-based. A total of 47,209 patients who presented with COPD between January 2012 and December 2016 were included. The average Hb level during hospitalization was used as the $\mathrm{Hb}$ level. CKD and advanced CKD were defined as estimated glomerular filtration rates $<60 \mathrm{and}<30 \mathrm{ml} /$ $\mathrm{min} / 1.73 \mathrm{~m}^{2}$, respectively. The association between $\mathrm{Hb}$ level (measured in $1 \mathrm{~g} / \mathrm{dL}$ intervals) and in-hospital mortality was analyzed in different multivariable logistic regression models by CKD stratification.
\end{abstract}

Results: The Hb level was decreased in the CKD subgroup. In the non-CKD group, a higher Hb level was not associated with an increased risk of in-hospital death. However, the $\mathrm{Hb}$ level and mortality showed a U-shaped relationship in the CKD group. After adjusting for age and Charlson Comorbidity Index, multivariable regression analysis showed that an $\mathrm{Hb}$ level $>17 \mathrm{~g} / \mathrm{dL}$ was associated with an increased risk of death in the CKD group with an odds ratio (OR) of $2.085(95 \% \mathrm{Cl}, 1.019-4.264)$. $\mathrm{Hb}>14 \mathrm{~g} / \mathrm{dL}$ was related to an increased risk of death in advanced CKD patients $(\mathrm{OR}, 4.579(95 \% \mathrm{Cl}, 1.243-16.866))$.

Conclusions: High $\mathrm{Hb}$ is associated with an increased risk of in-hospital death in COPD patients with CKD, especially among those with advanced CKD. In this group of patients, attention should be paid to those with high $\mathrm{Hb}$ levels.

Keywords: Hemoglobin abnormality, In-hospital mortality, Polycythemia, Population-based study, China collaborative study on acute kidney injury (CCS-AKI), Chronic obstructive pulmonary disease

\footnotetext{
*Correspondence: shiweigz@126.com; xinlingliang_ggh@163.com

'Libin Xu and Yuanhan Chen contributed equally to this study.

'The Second School of Clinical Medicine, Southern Medical University, Guangzhou 510515, China

2Division of Nephrology, Guangdong Provincial People's Hospital, Guangdong Academy of Medical Sciences, Guangzhou 510080, China

Full list of author information is available at the end of the article
}

(c) The Author(s). 2019 Open Access This article is distributed under the terms of the Creative Commons Attribution 4.0 International License (http://creativecommons.org/licenses/by/4.0/) which permits unrestricted use, distribution, and reproduction in any medium, provided you give appropriate credit to the original author(s) and the source, provide a link to the Creative Commons license, and indicate if changes were made. The Creative Commons Public Domain Dedication waiver (http://creativecommons.org/publicdomain/zero/1.0/) applies to the data made available in this article, unless otherwise stated. 


\section{Background}

Chronic obstructive pulmonary disease (COPD) is characterized by chronic airflow limitation, inflammation and lung remodeling. In 2020, COPD is projected to rank fifth worldwide in terms of disease burden and third in terms of mortality [1].

Hemoglobin $(\mathrm{Hb})$ abnormalities, including anemia and polycythemia, are common in the COPD population [24]. As hypoxia promotes erythropoiesis, COPD has long been recognized as an important cause of secondary polycythemia. Polycythemia contributes to the development of cor pulmonale and pulmonary hypertension, which are linked to poor prognosis [5]. However, polycythemia prevalence rates reported in recent studies are lower than those in earlier studies and range from 6 to $10 \%$ in the COPD population $[2,6,7]$, likely due to widespread prescription of long-term oxygen therapy [8].

The association of polycythemia and adverse outcomes is not well understood in patients with COPD. Several previous studies indicated a neutral or protective role of polycythemia $[2,6,7]$. In COPD patients with chronic respiratory failure, polycythemic subjects seemed to have a higher survival rate than normocythemic subjects [9]. Similar results were observed in studies using hematocrit as a polycythemic index. In a small sample cohort study, the hematocrit level was comparable in survivors and nonsurvivors [10]. In another COPD cohort including 2524 patients, the 3 -year survival was $24 \%$ when the hematocrit was $<35$ and $70 \%$ when the hematocrit was $\geq 55 \%$ [11].

However, the potential detrimental effects of polycythemia have been implicated in several other chronic conditions, one of which is chronic kidney disease (CKD). Serial randomized controlled trials (RCTs) and metaanalyses have demonstrated the risks of relatively higher $\mathrm{Hb}$ concentrations. These increased risks include stroke, hypertension, vascular access thrombosis, cardiovascular events, end-stage renal disease and death, and the cutoff values of high $\mathrm{Hb}$ did not exceed those of polycythemia [12-16]. Based on this evidence, the anemia guidelines of the Kidney Disease Outcomes Quality Initiative (KDOQI), which were updated in 2007, recommended an upper target of $12 \mathrm{~g} / \mathrm{dL}$ for $\mathrm{Hb}$ and suggested that $\mathrm{Hb}$ levels should not exceed $13 \mathrm{~g} / \mathrm{dL}$ [17]. Later, the 2012 anemia practice guidelines of the Kidney Disease: Improving Global Outcomes (KDIGO) group recommended that the upper target of $\mathrm{Hb}$ should be $11.5 \mathrm{~g} / \mathrm{dL}$ and that $\mathrm{Hb}$ levels should not exceed $13 \mathrm{~g} / \mathrm{dL}$ [18].

CKD is a common comorbidity in the COPD population $[4,8,19]$. Given the effect of $\mathrm{CKD}$ on $\mathrm{Hb}$, does $\mathrm{CKD}$ affect the $\mathrm{Hb}$ distribution among COPD patients? Furthermore, due to the detrimental role of high $\mathrm{Hb}$ in the CKD population, does high $\mathrm{Hb}$ pose a more serious threat to COPD patients with CKD than to those without CKD? In this hospital population-based study, we aimed to compare the difference in $\mathrm{Hb}$ distribution in non-CKD and CKD patients with COPD and then separately study the relationship between high $\mathrm{Hb}$ and in-hospital mortality. The reference $\mathrm{Hb}$ intervals in the COPD population were also explored.

\section{Methods}

\section{Study subjects}

Electronic data of COPD patients from the 13 hospitals included in the database of the China Collaborative Study on Acute Kidney Injury (CCS-AKI, a multicenter observational study led by Guangdong Provincial People's Hospital) were retrospectively analyzed. This dataset includes all hospitalized COPD patients with or without AKI. All patients were admitted to the hospital between January 2012 and December 2016, and the electronic data consisted of demographic information, diagnostic determination, and results of serum creatinine and $\mathrm{Hb}$ tests. The creatinine values from the centers were calibrated by the Clinical Laboratory Center of Guangdong General Hospital.

Medical records from 78,036 admissions with COPD suitable for the purpose of this study were screened. COPD and the acute phase were judged according to clinical diagnostic coding. Twelve hospitals were tertiary hospitals, and 1 was a secondary hospital (the detailed information regarding the included hospitals is summarized in Additional file 1: Table S1). The exclusion criteria were as follows: 1 ) incorrect/incomplete data; 2 ) $<18$ years or from the pediatric ward or $>90$ years; 3 ) anemia that might influence in-hospital death, including myelophthisic anemia, myelodysplastic syndrome, aplastic anemia, thalassemia, hemolytic anemia, or anemia due to significant blood loss; 4) Hb fluctuation (the maximum value minus the minimum value) $>2 \mathrm{~g} / \mathrm{dL}$ during the hospital stay; and 5) hospital stay $>30 \mathrm{~d}$. For patients with multiple hospitalizations, data from the last admission were used for analysis. The flow chart of population selection is shown in Fig. 1. Ultimately, a total of 47,209 patients were recruited in this study.

\section{Definitions and outcome}

CKD was defined as an estimated glomerular filtration rate $(\mathrm{eGFR})<60 \mathrm{ml} / \mathrm{min} / 1.73 \mathrm{~m}^{2}$, which was based on the lowest serum creatinine level within 12 months before discharge of the latest hospitalization, according to the KDOQI guidelines [20]. In-hospital death was the main outcome, and the $\mathrm{Hb}$ interval at the minimum death rate was defined as the reference interval. The Charlson Comorbidity Index (CCI) was used as the primary risk index for in-hospital death [2, 21]. Considering the inconsistency in the International Classification of Disease (ICD) standards among the enrolled study centers, ICD 


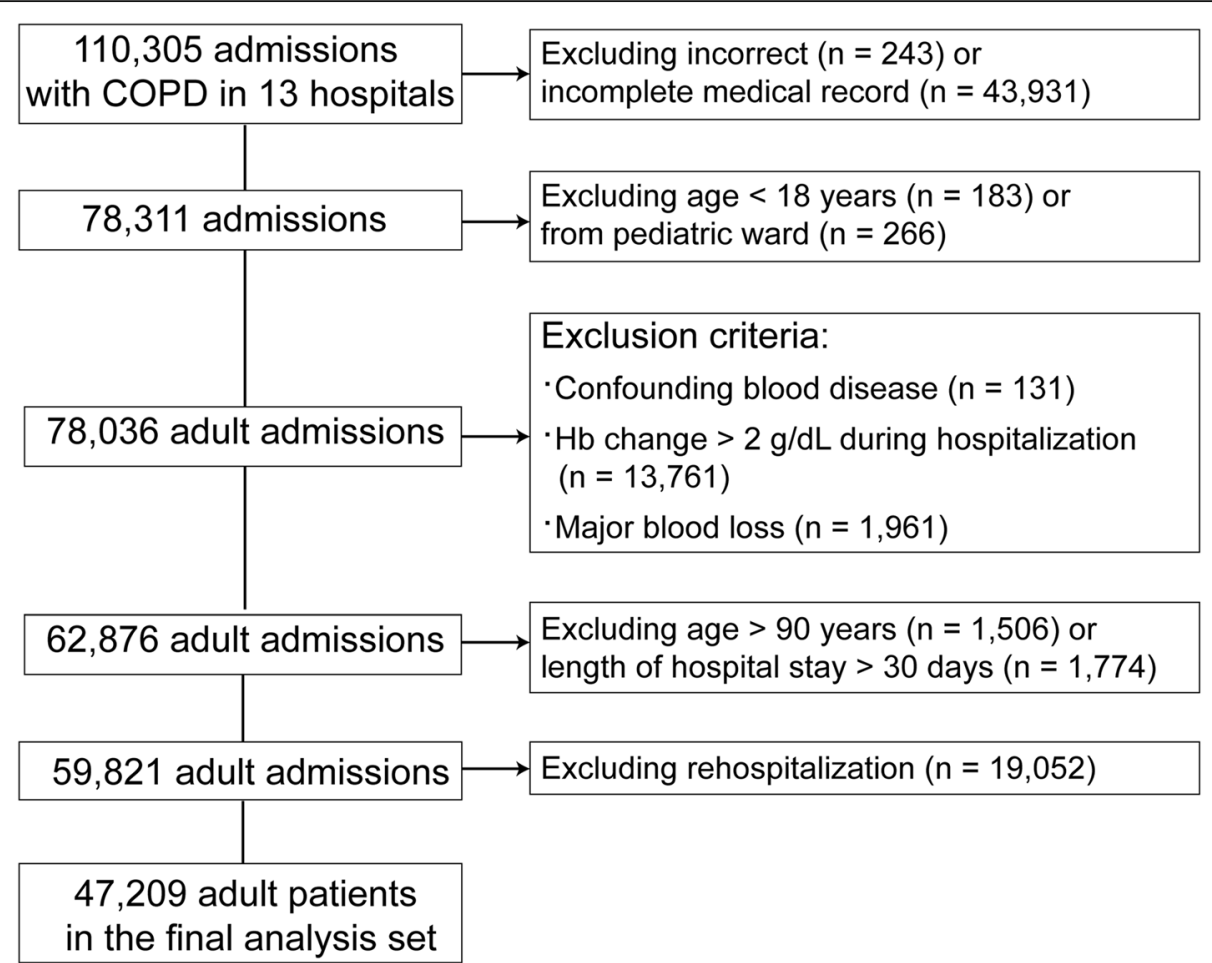

Fig. 1 Flow chart of the study population selection

codes and diagnostic nomenclature were both used to calculate CCI. The mean $\mathrm{Hb}$ level during hospitalization for each patient was used as the $\mathrm{Hb}$ level for subsequent analysis.

\section{Grouping and subgrouping}

The enrolled patients were divided into a CKD group and a non-CKD group. To analyze the influence of the severity of CKD on $\mathrm{Hb}$, the CKD group was further divided into an early CKD group (eGFR, $30-59 \mathrm{ml} / \mathrm{min} / 1.73 \mathrm{~m}^{2}$ ) and an advanced CKD group (eGFR $\left.<30 \mathrm{ml} / \mathrm{min} / 1.73 \mathrm{~m}^{2}\right)$.

Normally, males have a higher $\mathrm{Hb}$ level than females. According to the original design of this study, the patients were also subgrouped based on sex. However, in the CKD population, the male patients did not show a significant difference in $\mathrm{Hb}$ levels compared with the female patients. Although females showed slightly higher $\mathrm{Hb}$ levels than males during the progression of CKD, no significant difference was observed (Additional file 1: Figure S1). Therefore, stratification based on sex was not taken into consideration during subsequent analysis.

\section{Statistical analysis}

Measurement data are presented as the means \pm standard deviation or medians (Q25-Q75). Independent t-tests were used for comparison between groups. Numeration data are presented as percentages (\%), and $\chi^{2}$ tests were used for comparison between groups. Multivariable logistic regression was performed to analyze the risk of in-hospital death, and odds ratios (ORs) and 95\% confidential intervals $(95 \% \mathrm{CIs})$ were calculated. Age and CCI were included as variables. All statistical analyses were performed using SPSS 24.0. A two-tailed $P$ value $<0.05$ was considered to indicate a significant difference.

\section{Results}

General data

Of the included 47,209 patients with COPD, 6808 (14.4\%) patients also had CKD. Patients in the CKD group were older and had more complications (e.g., cardiovascular diseases and diabetes) than those in the non-CKD group (Table 1).

\section{$\mathrm{Hb}$ distribution based on the CKD stratification}

The average $\mathrm{Hb}$ level of the total population was $13.4 \pm$ $2.4 \mathrm{~g} / \mathrm{dL}$, with a median $(\mathrm{Q} 25, \mathrm{Q} 75)$ of $13.4(12.0,14.8) \mathrm{g} /$ $\mathrm{dL}$. Furthermore, $\mathrm{Hb}$ distribution frequencies were plotted based on intervals of $1 \mathrm{~g} / \mathrm{dL}$ according to clinical judgment and preliminary analysis (Fig. 2). The $\mathrm{Hb}$ distribution was similar between the non-CKD group and the total population. However, the CKD group showed a left-shifted distribution curve, particularly the advanced CKD group.

In-hospital death risk based on different $\mathrm{Hb}$ intervals A total of 640 patients (1.4\%) died during their hospital stays. The death rates of the non-CKD group and CKD 
Table 1 Clinical characteristics of the study subjects

\begin{tabular}{|c|c|c|}
\hline & Non-CKD & CKD \\
\hline Age (years) & $68.9 \pm 11.9$ & $77.5 \pm 8.4$ \\
\hline Male [n (\%)] & $25,624(63.4 \%)$ & $4275(62.8 \%)$ \\
\hline $\mathrm{eGFR}\left(\mathrm{ml} / \mathrm{min} / 1.73 \mathrm{~m}^{2}\right)$ & $88.9 \pm 14.9$ & $44.6 \pm 13.6$ \\
\hline Length of hospital stay (days) & $10(7,14)$ & $10(6,13)$ \\
\hline \multicolumn{3}{|l|}{ Comorbidity [n (\%)] } \\
\hline Cor pulmonale & $12,889(31.9 \%)$ & $1860(27.3 \%)$ \\
\hline Hypertension & 13,695 (33.9\%) & $3621(53.2 \%)$ \\
\hline Myocardial infarction & $1374(3.4 \%)$ & $458(6.7 \%)$ \\
\hline Congestive heart failure & $14,883(36.8 \%)$ & $3195(46.9 \%)$ \\
\hline Peripheral disease & $6192(15.3 \%)$ & $1585(23.3 \%)$ \\
\hline Cerebrovascular disease & $6119(15.1 \%)$ & $1545(22.7 \%)$ \\
\hline Dementia & $239(0.6 \%)$ & $81(1.2 \%)$ \\
\hline Connective tissue disease & $690(1.7 \%)$ & $170(2.5 \%)$ \\
\hline Peptic ulcer disease & $346(0.9 \%)$ & $74(1.1 \%)$ \\
\hline Mild liver disease & $4773(11.8 \%)$ & $1070(15.7 \%)$ \\
\hline $\begin{array}{l}\text { Diabetes without end-organ } \\
\text { damage }\end{array}$ & $4774(11.8 \%)$ & $1144(16.8 \%)$ \\
\hline Hemiplegia & $47(0.1 \%)$ & $8(0.1 \%)$ \\
\hline $\begin{array}{l}\text { Diabetes with end-organ } \\
\text { damage }\end{array}$ & $604(1.5 \%)$ & $312(4.6 \%)$ \\
\hline Tumor without metastasis & $3139(7.8 \%)$ & 448 (6.6\%) \\
\hline Leukemia & $201(0.5 \%)$ & $71(1.0 \%)$ \\
\hline Lymphoma & $87(0.2 \%)$ & $18(0.3 \%)$ \\
\hline Moderate or severe liver disease & $158(0.4 \%)$ & $55(0.8 \%)$ \\
\hline Metastatic solid tumor & $1221(3.0 \%)$ & $225(3.3 \%)$ \\
\hline AIDS & $50(0.1 \%)$ & $4(0.1 \%)$ \\
\hline Charlson Comorbidity Index & $2(1,3)$ & $3(2,4)$ \\
\hline \multicolumn{3}{|l|}{ Medications [n (\%)] } \\
\hline $\begin{array}{l}\text { Antibiotics or antifungal } \\
\text { agents }\end{array}$ & $21,054(52.1 \%)$ & $3705(54.4 \%)$ \\
\hline ACEls or ARBs & $8034(19.9 \%)$ & $1786(26.2 \%)$ \\
\hline Diuretics $^{a}$ & $8597(21.3 \%)$ & $2123(31.2 \%)$ \\
\hline Vasoactive drugs & $2212(5.5 \%)$ & $683(10.0 \%)$ \\
\hline
\end{tabular}

eGFR estimated glomerular filtration rate, $A C E I$ angiotensin-converting enzyme inhibitor; $A R B$ angiotensin II receptor antagonist

${ }^{a}$ including antihypertensive drug combination

group were 1.0 and $3.3 \%$, respectively, showing a significant difference $\left(\chi^{2}=222.64, P<0.001\right)$.

Compared with the subgroups with $\mathrm{Hb}<10 \mathrm{~g} / \mathrm{dL}$, the death rate decreased among those with $\mathrm{Hb} 10-16 \mathrm{~g} / \mathrm{dL}$ in both the non-CKD and CKD groups (Fig. 3a). The death rate tended to further decrease in the non-CKD patients with increased $\mathrm{Hb}$. However, in the CKD group, the death rate showed a U-shaped distribution pattern with changes in $\mathrm{Hb}$. $\mathrm{Hb}$ levels and mortality rate were inversely proportional when the $\mathrm{Hb}$ level was above 16 g/dL (Fig. 3a). Unsurprisingly, this U-shaped pattern was more noticeable in the advanced CKD group (Fig. 3b and Additional file 1: Figure S2).

Furthermore, the association between a high $\mathrm{Hb}$ level and in-hospital mortality was tested using a multivariable logistic regression model that included age $(\leq 55$ years, 56-75 years and $>75$ years) and CCI scores as the covariates. The outcomes of the multivariable analysis were similar to those of the univariate analysis. For the non-CKD group, although mortality increased when the $\mathrm{Hb}$ level was below the $12-13 \mathrm{~g} / \mathrm{dL}$ interval (the reference interval), a higher $\mathrm{Hb}$ level above this interval was not significantly associated with increased mortality (Fig. 4a). For the CKD group, however, Hb levels $>17 \mathrm{~g} /$ $\mathrm{dL}$ were associated with a higher risk of death, with an OR of 2.085 (95\% CI 1.019-4.264, $P=0.044$ ) (Fig. 4b). The analysis based on the severity of CKD showed no association between a high $\mathrm{Hb}$ level and in-hospital mortality in the early CKD group (Fig. 4c). In the advanced CKD group, however, the mortality rates associated with $\mathrm{Hb}$ levels of $15-16 \mathrm{~g} / \mathrm{dL}, 16-17 \mathrm{~g} / \mathrm{dL}$ and $>17 \mathrm{~g} / \mathrm{dL}$ were 4.8-8.8 times higher than those associated with $\mathrm{Hb}$ levels within the reference interval (Additional file 1: Figure S3). After the subgroups with Hb levels $>14 \mathrm{~g} / \mathrm{dL}$ were merged, the mortality ORs corresponding to $\mathrm{Hb}$ levels of $13-14 \mathrm{~g} / \mathrm{dL}$ and $>14 \mathrm{~g} / \mathrm{dL}$ were 4.000 (95\% CI, $0.954-16.772, P=0.058)$ and 4.579 (95\% CI, 1.24316.866, $P=0.022$ ), respectively (Fig. $4 d$ ).

\section{Discussion}

The results of the present study of the hospitalized COPD population are in accordance with those of other reports showing the effect of CKD on anemia [4] and the associations of anemia with increased mortality [2]. We extended these previous observations by showing the association between high $\mathrm{Hb}$ concentration and inhospital death in CKD patients, which was particularly significant in the advanced CKD group. Based on the analysis of the serial $\mathrm{Hb}$ intervals, the upper reference interval of $\mathrm{Hb}$ was $17 \mathrm{~g} / \mathrm{dL}$ for $\mathrm{CKD}$ and $14 \mathrm{~g} / \mathrm{dL}$ for advanced CKD. According to these preliminary reference intervals, high $\mathrm{Hb}$ levels were observed in 275 patients (4.0\%) with CKD and 116 patients (10.8\%) with advanced CKD.

A high $\mathrm{Hb}$ concentration is double-edged. It not only is considered an adaptive physiological response to hypoxemia in the COPD population [22] but also plays a detrimental role in CKD [12-16]. The mechanism of the association between high $\mathrm{Hb}$ and death is unclear. Several hypotheses have been suggested, including increased blood volume and viscosity and improved platelet function after correction of anemia [23, 24]. These mechanisms cause hyperviscosity of the blood and contribute to increased pulmonary vascular resistance. Thromboembolic disease attributed to polycythemia affecting the 

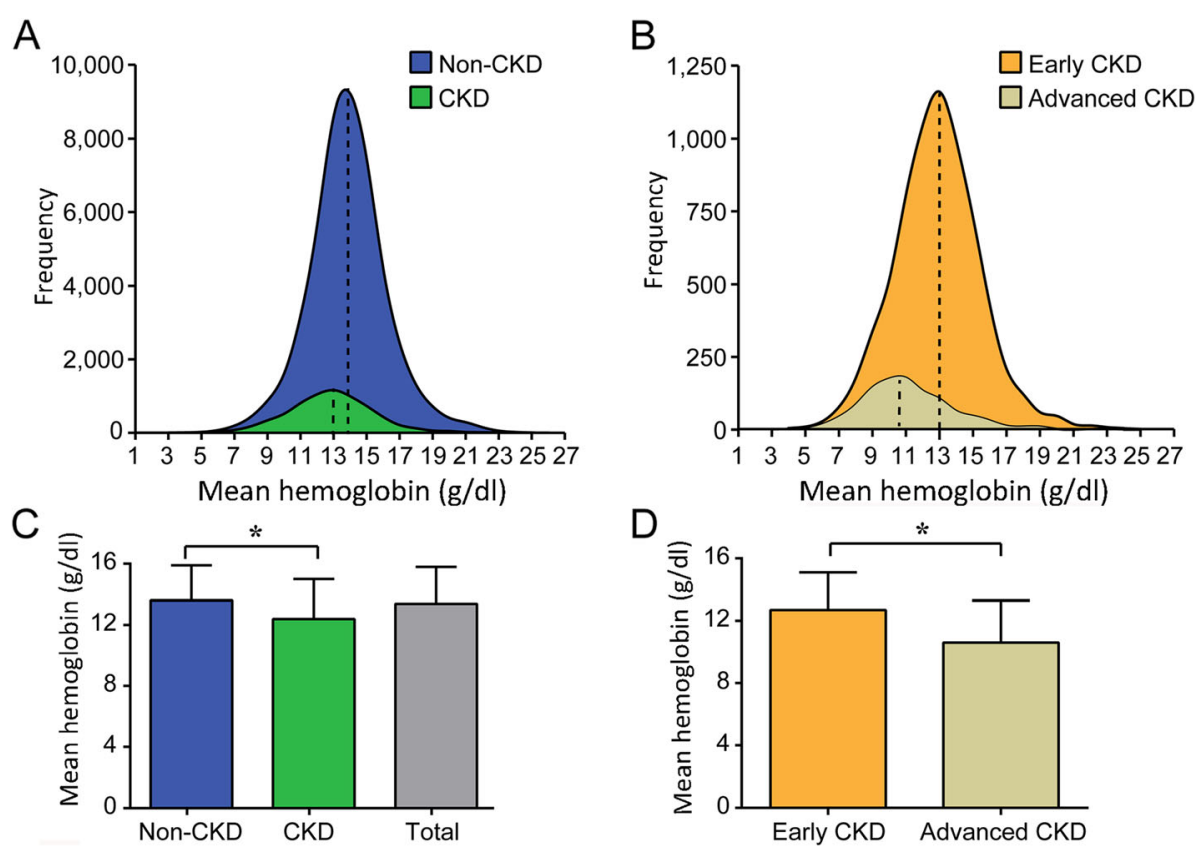

Fig. $2 \mathrm{Hb}$ distribution based on CKD stratification. a, Compared with the non-CKD group, the CKD group showed a left-shifted Hb distribution curve. b. Compared with the early CKD group, the advanced group showed a noticeable left-shifted distribution curve. $\mathbf{c}$, The CKD group had lower Hb levels than the non-CKD group. $\mathbf{d}$, The advanced CKD group had lower $\mathrm{Hb}$ levels than the early CKD group. The dashed lines in panels $\mathrm{A}$ and $\mathrm{B}$ indicate the median $\mathrm{Hb}$ levels of each subgroup. ${ }^{*} P<0.001$

pulmonary vascular bed again increases pulmonary vascular resistance. Polycythemia also inhibits the endothelial-dependent relaxation response to acetylcholine $[25,26]$. In addition, erythropoiesis-stimulating agents and iron may play detrimental roles independent of their therapeutic roles in hemopoiesis $[14,24,27-$ 30].

No previous studies have reported a clinical threat of a high $\mathrm{Hb}$ level in COPD patients $[6,7,31]$. In such studies, the authors defined a high $\mathrm{Hb}$ level based on the standard for polycythemia, i.e., $>17 \mathrm{~g} / \mathrm{dL}$ for males and $>15 \mathrm{~g} / \mathrm{dL}$ for females. The study subjects were primarily stable COPD outpatients whose pathogenetic conditions were less severe and who had a lower mortality than inpatients, and patients with heart disease, kidney disease and malignancies were often excluded, as these conditions might serve as confounding diseases of COPD [6, 7, 31]. Compared with these studies, the current study showed the following noticeable differences: 1 ) The current study adopted $\mathrm{Hb}$ intervals of $1 \mathrm{~g} / \mathrm{dL}$, rather than the polycythemia standard, to explore a possible
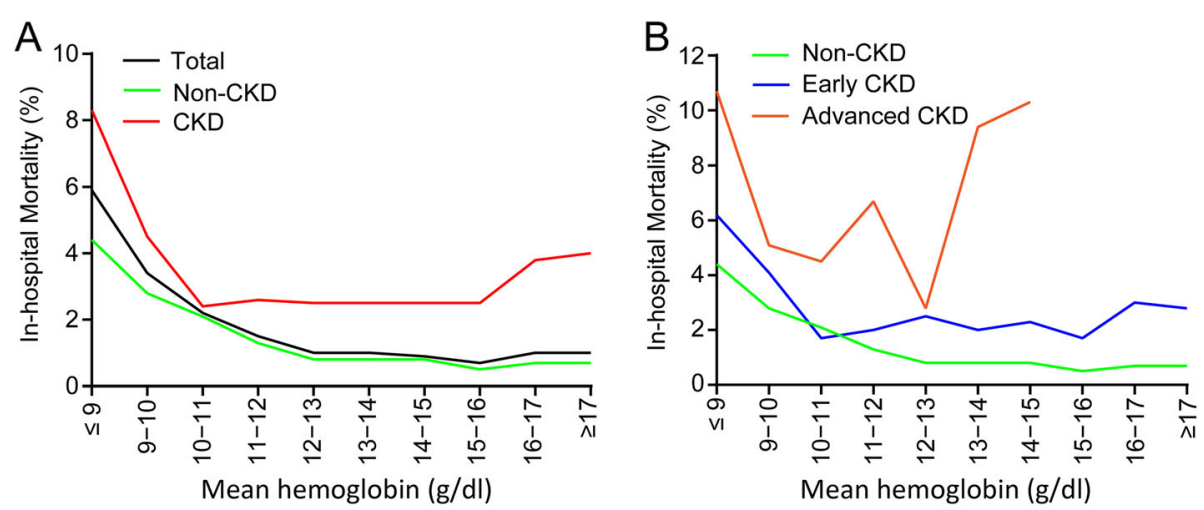

Fig. 3 Relation between in-hospital mortality and Hb levels. $\mathbf{a}$, The patients were stratified by non-CKD or CKD. $\mathbf{b}$, The patients were stratified by non-CKD, early CKD or advanced CKD. As the number of patients with $\mathrm{Hb}$ levels $>14 \mathrm{~g} / \mathrm{dL}$ was small in the advanced CKD group, the groups within intervals above $14 \mathrm{~g} / \mathrm{dL}$ were merged 


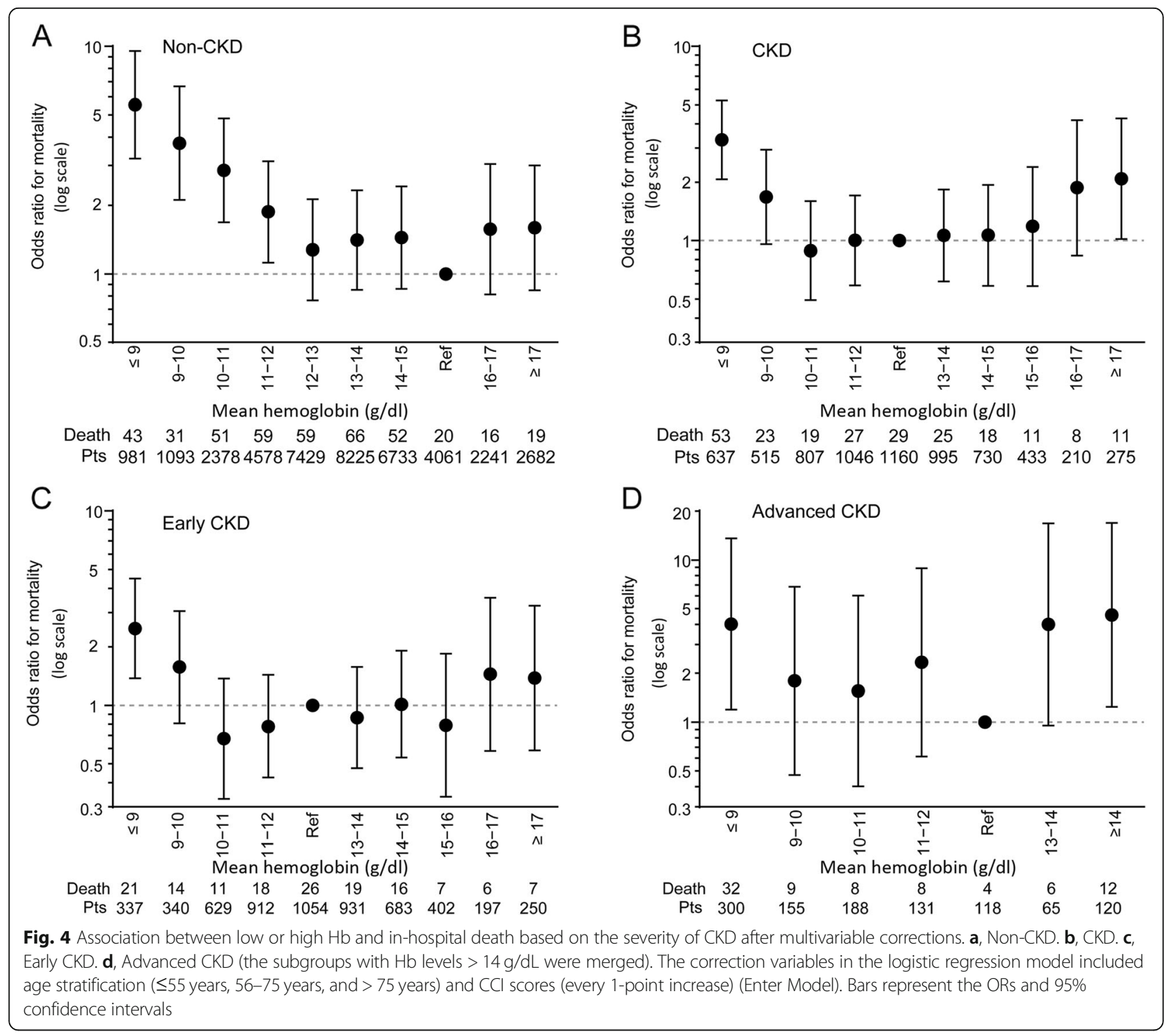

reference $\mathrm{Hb}$ level based on the mortality of patients within different $\mathrm{Hb}$ intervals. 2) The current study did not exclude COPD patients with other diseases except for hematologic disease and hemorrhagic disease, which could possibly have had an influence on mortality, making the study subjects more representative. 3) The CCI was used for correction of the influence of multiple complications on mortality, although the small number of death-related residual confounding factors of the COPD patients was not corrected for [8]; the scoring system successfully covered most of the death-related comorbidities. 4) Most importantly, this study adopted the presence of CKD and the severity of CKD as stratification standards. These features not only explain the major differences between this study and previous studies but also allow the current team to move forward to explore the upper reference limit for $\mathrm{Hb}$ in COPD patients.
The exploration of the optimal upper $\mathrm{Hb}$ target in the CKD population has gone through a long journey. In early studies, exploring the optimal $\mathrm{Hb}$ target was difficult due to the considerable heterogeneity in the criterion for high $\mathrm{Hb}$ [16]. Only in recent years have a number of representative registered clinical trials (the Cardiovascular Risk Reduction by Early Anemia Treatment with Epoetin Beta (CREATE), the Correction of Hemoglobin and Outcomes in Renal Insufficiency (CHOIR) and the Trial to Reduce Cardiovascular Events with Aranesp Therapy (TREAT)) reported higher target $\mathrm{Hb}$ concentrations of $13-15,13.5$ and $13.5 \mathrm{~g} / \mathrm{dL}$, respectively [12-14]. The results of these studies demonstrated the association between a higher $\mathrm{Hb}$ target level and a higher death risk and became the important basis for the KDOQI and KDIGO guidelines. A meta-analysis that 
summarized 9 registered clinical trials, where the high $\mathrm{Hb}$ targets were set between $13 \mathrm{~g} / \mathrm{dL}$ and $16 \mathrm{~g} / \mathrm{dL}$, showed that an $\mathrm{Hb}$ target within $12-16 \mathrm{~g} / \mathrm{dL}$ was associated with a high risk of death [15]. However, none of these trials focused on the COPD population. In this study, we investigated the risks associated with high $\mathrm{Hb}$ in a COPD population based on CKD stratification for the first time. While exploring the upper reference limit for $\mathrm{Hb}$, the current team adopted a stratification method to avoid the interaction of CKD with abnormal $\mathrm{Hb}$ levels. The results of this study showed that the guidelines regarding the upper reference limit for $\mathrm{Hb}$ in the COPD population with CKD were similar to those in the CKD population, suggesting that management of anemia for CKD patients may serve as a reference for the treatment of COPD complicated with CKD and that the upper reference limit for $\mathrm{Hb}$ should also be taken into consideration. These results provide evidence for future work on optimal $\mathrm{Hb}$ limits.

This study has the following limitations. First, the CCS-AKI databank suffers from a lack of information regarding erythropoietin- and COPD-related medicine and hematologic testing indices except for $\mathrm{Hb}$, as the initial designed endpoint of the databank was renal events. Therefore, the potential influence of these factors on mortality failed to be corrected for. Second, because the data were derived from retrospective electronic medical records, supplemental oxygen use, pulmonary function and blood gas analysis indices were not available, and the severity of hypoxia and patient conditions were not evaluated. Thus, the impact of a high $\mathrm{Hb}$ level could not be assessed independent of the severity of COPD. In addition, approximately $40 \%$ of subjects were excluded due to incorrect or incomplete medical records (Fig. 1), which might cause selection bias. Third, the adverse outcome observed in this study was limited to in-hospital mortality, and other adverse events, such as quality of life, cardiovascular events, shock and long-term death, were not included. Therefore, the possibility that the mechanisms underlying the influence of high $\mathrm{Hb}$ on these adverse events were different from those underlying mortality cannot be excluded. Finally, Hb levels in actual clinical practice may not be consistent with the target limits for $\mathrm{Hb}$ management. Therefore, the optimal $\mathrm{Hb}$ target limit for the COPD population with CKD remains to be confirmed in future studies.

\section{Conclusions}

In conclusion, high $\mathrm{Hb}$ was associated with an increased risk of in-hospital death in the COPD population with CKD, especially those COPD patients with advanced CKD. The management of erythrocyte abnormalities in COPD should not be limited to anemia, but due attention should be given to CKD stratification and increased $\mathrm{Hb}$ levels.

\section{Additional file}

Additional file 1: Table S1. Information on the enrolled hospitals. Figure S1. Comparison of the Hb levels between males and females in the COPD population complicated with CKD. Figure S2. In-hospital mortality at different $\mathrm{Hb}$ levels using uncombined data in the advanced CKD group. The subgroups of the advanced CKD group with Hb levels > $14 \mathrm{~g} / \mathrm{dL}$ were not merged. In the advanced CKD group, the mortalities of the subgroups with $\mathrm{Hb}$ levels of $13-14 \mathrm{~g} / \mathrm{dL}, 14-15 \mathrm{~g} / \mathrm{dL}, 15-16 \mathrm{~g} / \mathrm{dL}$, $16-17 \mathrm{~g} / \mathrm{dL}$ and higher than $17 \mathrm{~g} / \mathrm{dL}$ were $9.4,4.3,12.9,15.4$, and $16.0 \%$, respectively. Points $\mathrm{a}, \mathrm{b}$ and $\mathrm{c}$ indicate the lowest mortalities of the non-CKD group (0.5\%), the early CKD group (1.7\%), and the advanced CKD group (2.8\%), respectively. Figure S3. Association between low or high $\mathrm{Hb}$ levels and in-hospital death using uncombined data in the advanced CKD group. The subgroups with Hb levels $>14 \mathrm{~g} / \mathrm{dL}$ were not merged. Compared with the reference interval (12-13 g/dL), Hb levels of $15-16 \mathrm{~g} / \mathrm{dL}, 16-17 \mathrm{~g} / \mathrm{dL}$ and $>17 \mathrm{~g} / \mathrm{dL}$ significantly increased patient mortality, with ORs of $5.831(95 \% \mathrm{Cl}, 1.209-28.113), 7.417(95 \% \mathrm{Cl}$ $1.083-50.796)$ and $8.781(95 \% \mathrm{Cl}, 1.781-43.284)$, respectively. Bars represent the ORs and 95\% confidence intervals. (DOC $1185 \mathrm{~kb}$ )

\section{Abbreviations}

CKD: Chronic kidney disease; COPD: Chronic obstructive pulmonary disease; Hb: Hemoglobin; KDOQI: Kidney Disease Outcomes Quality Initiative

\section{Acknowledgments}

Not applicable.

\section{Authors' contributions}

Conceptualization, XLB, CYH, and SW; Methodology, XZ; Software, XZ and CSX; Validation, HQ, CSX and WWJ; Formal analysis, LGH and LYJ; Investigation, WWJ and LYJ; Resources, LC; Data curation, LC, HL and SJ; Writing-Original draft preparation, XLB and $\mathrm{CYH}$; Writing-Review \& editing, LXL; Visualization, CYH; Supervision, LXL; Project administration, SW; Funding acquisition, LXL. All authors have made their contributions to this work and have approved this submission.

\section{Funding}

This study was financially supported by Guangdong Science and Technology Project (2017A070709008) and Guangzhou Science and Technology Project (201604020037)

The funders had no role in the design of the study, the collection, analysis and interpretation of the data, or preparation of the manuscript.

\section{Availability of data and materials}

All data generated or analyzed during this study are included in this article and its supplementary information files.

\section{Ethics approval and consent to participate}

The procedures of this study were performed in accordance with medical ethics and the Helsinki Declaration and approved by the Ethics Committee of Guangdong General Hospital. Considering that this study was retrospective, written informed consent was waived by the ethics committee. The registered clinical trial number was NCT03054142.

Consent for publication

Not applicable.

\section{Competing interests}

The authors declare that they have no competing interests.

\section{Author details}

1The Second School of Clinical Medicine, Southern Medical University, Guangzhou 510515, China. ²Division of Nephrology, Guangdong Provincial People's Hospital, Guangdong Academy of Medical Sciences, Guangzhou 510080, China. ${ }^{3}$ Department of Nephrology, Inner Mongolia People's 
Hospital, Hohhot 010017, China. ${ }^{4}$ Department of Dermatology, Sichuan Academy of Medical Sciences and Sichuan Provincial People's Hospital, Chengdu 610072, China. ${ }^{5}$ Department of Nephrology, Zhejiang Provincial People's Hospital (People's Hospital of Hangzhou Medical College), Hangzhou 310014, China. ${ }^{6}$ Division of Preventive Medicine, School of Public Health, Guangzhou Medical University, Guangzhou 510515, China. ${ }^{7}$ Division of Nephrology, Shanghai Ninth People's Hospital, School of Medicine, Shanghai Jiaotong University, Shanghai 200030, China. ${ }^{8}$ Department of Nephrology, Dongguan People's Hospital, Dongguan 523018, China. 'Department of Nephrology, Chongqing Ninth People's Hospital, Chongqing 400700, China. ${ }^{10}$ Department of Nephrology, People's Hospital of Xinjiang Uygur Autonomous Region, Urumqi 830001, China. ${ }^{11}$ Department of Nephrology, Second Hospital of Anhui Medical University, Hefei 230601, China. ${ }^{12}$ Department of Nephrology, Second Hospital of Jilin University, Changchun 130022, China.

\section{Received: 28 January 2019 Accepted: 28 August 2019}

Published online: 18 September 2019

\section{References}

1. Rabe KF, Hurd S, Anzueto A, Barnes PJ, Buist SA, Calverley P, et al. Global strategy for the diagnosis, management, and prevention of chronic obstructive pulmonary disease: GOLD executive summary. Am J Respir Crit Care Med. 2012;176:532-55.

2. Cote C, Zilberberg MD, Mody SH, Dordelly L, Celli B. Haemoglobin level and its clinical impact in a cohort of patients with COPD. Eur Respir J. 2007; 29:923-9.

3. Vasquez A, Logomarsino JV. Anemia in chronic obstructive pulmonary disease and the potential role of iron deficiency. COPD. 2016;13:100-9.

4. John M, Lange A, Hoernig S, Witt C, Anker SD. Prevalence of anemia in chronic obstructive pulmonary disease: comparison to other chronic diseases. Int J Cardiol. 2006;111:365-70.

5. Criner GJ. Effects of long-term oxygen therapy on mortality and morbidity. Respir Care. 2000;45:105-18.

6. Ferrari M, Manea L, Anton K, Bruzzone P, Meneghello M, Zamboni F, et al. Anemia and hemoglobin serum levels are associated with exercise capacity and quality of life in chronic obstructive pulmonary disease. BMC Pulm Med. 2015;15:58.

7. Boutou AK, Karrar S, Hopkinson NS, Polkey MI. Anemia and survival in chronic obstructive pulmonary disease: a dichotomous rather than a continuous predictor. Respiration. 2013;85:126-31.

8. Putcha N, Drummond MB, Wise RA, Hansel NN. Comorbidities and chronic obstructive pulmonary disease: prevalence, influence on outcomes, and management. Semin Respir Crit Care Med. 2015;36:575-91.

9. Kollert F, Tippelt A, Müller C, Jörres RA, Porzelius C, Pfeifer M, et al. Hemoglobin levels above anemia thresholds are maximally predictive for long-term survival in COPD with chronic respiratory failure. Respir Care. 2013;58:1204-12.

10. Kawakami Y, Kishi F, Yamamoto H, Miyamoto K. Relation of oxygen delivery, mixed venous oxygenation, and pulmonary hemodynamics to prognosis in chronic obstructive pulmonary disease. N Engl J Med. 1983;308:1045-9.

11. Chambellan A, Chailleux E, Similowski T. Prognostic value of the hematocrit in patients with severe COPD receiving long-term oxygen therapy. Chest. 2005;128:1201-8.

12. Drueke TB, Locatelli F, Clyne N, Eckardt KU, Macdougall IC, Tsakiris D, et al. Normalization of hemoglobin level in patients with chronic kidney disease and anemia. N Engl J Med. 2006;355:2071-84.

13. Singh AK, Szczech L, Tang KL, Barnhart H, Sapp S, Wolfson M, et al. Correction of anemia with epoetin alfa in chronic kidney disease. N Engl J Med. 2006;355:2085-98.

14. Skali H, Parving HH, Parfrey PS, Burdmann EA, Lewis EF, Ivanovich P, et al. Stroke in patients with type 2 diabetes mellitus, chronic kidney disease, and anemia treated with Darbepoetin alfa: the trial to reduce cardiovascular events with Aranesp therapy (TREAT) experience. Circulation. 2011;124:2903-8.

15. Phrommintikul A, Haas SJ, Elsik M, Krum H. Mortality and target haemoglobin concentrations in anaemic patients with chronic kidney disease treated with erythropoietin: a meta-analysis. Lancet. 2007;369:381-8.

16. Palmer SC, Navaneethan SD, Craig JC, Johnson DW, Tonelli M, Garg AX, et al. Meta-analysis: erythropoiesis-stimulating agents in patients with chronic kidney disease. Ann Intern Med. 2010;153:23-33.
17. Levin A, Rocco M. KDOQI clinical practice guideline and clinical practice recommendations for anemia in chronic kidney disease: 2007 update of hemoglobin target. Am J Kidney Dis. 2007;50:471-530.

18. Riella MC. Kidney disease: improving global outcomes (KDIGO) anemia work group. KDIGO clinical practice guideline for anemia in chronic kidney disease. Kidney Int Suppl. 2012;2:279-335.

19. Mapel D. Renal and hepatobiliary dysfunction in chronic obstructive pulmonary disease. Curr Opin Pulm Med. 2014;20:186-93.

20. Mehta RL, Burdmann EA, Cerdá J, Feehally J, Finkelstein F, García-García G, et al. Recognition and management of acute kidney injury in the International Society of Nephrology 0by25 global snapshot: a multinational cross-sectional study. Lancet. 2016:387:2017-25.

21. Sundararajan V, Henderson T, Perry C, Muggivan A, Quan H, Ghali WA. New ICD-10 version of the Charlson comorbidity index predicted in-hospital mortality. J Clin Epidemiol. 2004;57:1288-94.

22. Jyothula S, Safdar Z. Update on pulmonary hypertension complicating chronic obstructive pulmonary disease. Int J Chron Obstruct Pulmon Dis. 2009;4:351-63

23. Fishbane $\mathrm{S}$, Besarab A. Mechanism of increased mortality risk with erythropoietin treatment to higher hemoglobin targets. Clin J Am Soc Nephrol. 2007;2:1274-82.

24. Weiskopf RB, Feiner J, Hopf H, Viele MK, Watson JJ, Lieberman J, et al. Heart rate increases linearly in response to acute isovolemic anemia. Transfusion. 2003:43:235-40.

25. Defouilloy C, Teiger E, Sediame S, Andrivet P, Roudot-Thoraval F, Chouaid C, et al. Polycythemia impairs vasodilator response to acetylcholine in patients with chronic hypoxemic lung disease. Am J Respir Crit Care Med. 1998; 157(5 Pt 1):1452-60

26. Deem S, Berg JT, Kerr ME, Swenson ER. Effects of the RBC membrane and increased perfusate viscosity on hypoxic pulmonary vasoconstriction. J Appl Physiol. 2000;88:1520-8.

27. Eckardt KU. Erythropoietin and microvascular diabetic complications. Nephrol Dial Transplant. 2009;24:388-90.

28. Siamopoulos KC, Gouva C, Katopodis KP, Tzallas C, Nikolopoulos P, Papavasiliou EC, et al. Long-term treatment with EPO increases serum levels of high-density lipoprotein in patients with CKD. Am J Kidney Dis. 2006;48:242-9.

29. Bohlius J, Schmidlin K, Brillant C, Schwarzer G, Trelle S, Seidenfeld J, et al. Recombinant human erythropoiesis-stimulating agents and mortality in patients with cancer: a meta-analysis of randomised trials. Lancet. 2009;373:1532-42

30. Koulouridis I, Alfayez M, Trikalinos TA, Balk EM, Jaber BL. Dose of erythropoiesis-stimulating agents and adverse outcomes in CKD: a metaregression analysis. Am J Kidney Dis. 2013;61:44-56.

31. Celli BR, Cote CG, Marin JM, Casanova C, Montes de Oca M, Mendez RA, et al. The body-mass index, airflow obstruction, dyspnea, and exercise capacity index in chronic obstructive pulmonary disease. N Engl J Med. 2004;350:1005-12

\section{Publisher's Note}

Springer Nature remains neutral with regard to jurisdictional claims in published maps and institutional affiliations.

Ready to submit your research? Choose BMC and benefit from:

- fast, convenient online submission

- thorough peer review by experienced researchers in your field

- rapid publication on acceptance

- support for research data, including large and complex data types

- gold Open Access which fosters wider collaboration and increased citations

- maximum visibility for your research: over $100 \mathrm{M}$ website views per year

At $\mathrm{BMC}$, research is always in progress.

Learn more biomedcentral.com/submission 